Li Zeng • Jianliang Dai • Kang Ying • Enpeng Zhao

Wei Jin · Yin Ye · Jianfeng Dai · Jian Xu • Yi Xie

Yumin Mao

\title{
Identification of a novel human angiopoietin-like gene expressed mainly in heart
}

Received: November 22, 2002 / Accepted: December 11, 2002

\begin{abstract}
The angiopoietins are an important family of growth factors specific for vascular endothelium. Most of them bind to the TIE2 receptor and are related to regulation of angiogenesis. During large-scale DNA sequencing of the human fetal brain cDNA library, we cloned a novel human angiopoietin-like cDNA and termed it human angiopoietin-like 5 (ANGPTL5). Like other members of the angiopoietin family, $A N G P T L 5$-deduced protein also has an N-terminal cleavable signal peptide, a predicted coiled-coil domain, and a fibrinogen-like domain. The search against the human genome database indicated that ANGPTL5 maps to 11q22. Expression analysis of $A N G P T L 5$ shows that it is mainly expressed in adult human heart.
\end{abstract}

Key words Angiopoietin · Coiled-coil domain · Fibrinogenlike domain · Heart · ANGPTL5

Angiogenesis is important to normal embryogenesis and is also related to several pathophysiological conditions such as the growth of solid tumor, neovascularization in the retina, and some inflammatory diseases (Nishimura et al. 1999). Angiogenesis requires proliferation and migration of endothelial cells, leading to sprouting, growth, and remodeling of the initial network. Although the basic mechanism underlying angiogenesis is not yet fully understood, regulation of angiogenesis seems to depend on a balance between positive and negative regulation factors (Hanahan and Folkman 1996).

The angiopoietins are an important family of growth factors that are closely related to angiogenesis.

L. Zeng · J. Dai · K. Ying · E. Zhao · W. Jin · Y. Ye · J. Dai · J. Xu • Y. Xie · Y. Mao $(\bowtie)$

State Key Laboratory of Genetic Engineering, Institute of Genetics, School of Life Sciences, Fudan University, Shanghai 200433, P. R. China

Tel. +86-21-65643573; Fax +86-21-65642502

e-mail: ymmao@fudan.edu.cn

The first two authors contributed equally to this work.
Angiopoietin 1 (ANGPT1) was found originally as a ligand for TIE2 (tyrosine kinase with immunoglobulin and epidermal growth factor homology domains 2, also known as TEK) to regulate later stages of vascular development, stabilization, and maturation (Davis et al. 1996; Suri et al. 1996). Angiopoietin 2 (ANGPT2) also binds to TIE2, but ANGPT2 acts as an antagonist of ANGPT1 and destabilizes vascular networks (Maisonpierre et al. 1997). Both the targeted disruption of the ANGPT1 gene and the overexpression of $A N G P T 2$ lead to angiogenic deficits, which are similar to those seen in mice lacking TIE2. Angiopoietin 3 (ANGPT3, mouse) and angiopoietin 4 (ANGPT4) are probably interspecies orthologues, and both bind to TIE2. However, like ANGPT2, mouse ANGPT3 acts as an antagonist for TIE2, whereas, like ANGPT1, ANGPT4 acts as an agonist for TIE2 (Valenzuela et al. 1999). All members of angiopoietin are secreted proteins with a characteristic structure: an N-terminal cleavable signal peptide, an extended helical domain predicted to form dimeric or trimeric coiled-coils, a short linker peptide, and a fibrinogen-like domain in the C-terminal portion.

A novel cDNA clone was obtained from large-scale DNA sequencing of the human fetal brain cDNA library, which was constructed by our laboratory (Xu et al. 2001). The nucleotide sequence is available from GenBank under accession number AY169281. This 1.8-kb cDNA spans an open reading frame from nucleotide 55 to 1221 , encoding a putative 388 -amino acid protein with a predicted molecular mass of $44.1 \mathrm{kDa}$ and a predicted isoelectric point of 6.02 (Fig. 1a). An in-frame stop codon is found at position 22-24, and two putative polyadenylation signal AATAAAs are found near the $3^{\prime}$ end of the sequence. Therefore, we conclude that the coding sequence is complete.

By using BlastP, the deduced protein was found to be highly homologous with the angiopoietins mentioned earlier. The protein is also homologous to some angiopoietinlike genes, such as ANGPTL1 (Kim et al. 1999a), ANGPTL2 (Kim et al. 1999b), ANGPTL3 (Conklin et al. 1999), ANGPTL4 (Kim et al. 2000) (Fig. 2), and some other members of the fibrinogen protein superfamily, sharing about $30 \%-40 \%$ amino acid identity. All angiopoietin-like 
1 cacaaagagctgactgatatt tgaagaagtgttttcatctatccaagaaaaata 55 atgatgtctccatcccaagcctcactcttattcttaaatgtatgtatttttatttgtggagaagctgtacaaggt $\begin{array}{llllllllllllllllllllllllllllll}1 & \text { M } & \text { M } & \text { S } & \text { P } & \text { S } & \text { Q } & \text { A } & \text { S } & \text { L } & \text { L } & \text { F } & \text { L } & \text { N } & \text { V } & \text { C } & \text { I } & \text { F } & \text { I } & \text { C } & G & \text { E } & \text { A } & \text { V } & Q & G\end{array}$ 130 aactgtgtacatcattctacggactcttcagtagttaacattgtagaagatggatctaatgcaaaagatgaaagt $\begin{array}{llllllllllllllllllllllllll}26 & \mathrm{~N} & \mathrm{C} & \mathrm{V} & \mathrm{H} & \mathrm{H} & \mathrm{S} & \mathrm{T} & \mathrm{D} & \mathrm{S} & \mathrm{S} & \mathrm{V} & \mathrm{V} & \mathrm{N} & \mathrm{I} & \mathrm{V} & \mathrm{E} & \mathrm{D} & \mathrm{G} & \mathrm{S} & \mathrm{N} & \mathrm{A} & \mathrm{K} & \mathrm{D} & \mathrm{E} & \mathrm{S}\end{array}$ 205 aaaag taatgatactgtttgtaaggaagactgtgaggaatcatgtgatgttaaactaaaattacacgagaagaa $\begin{array}{llllllllllllllllllllllllll}51 & \mathrm{~K} & \mathrm{~S} & \boldsymbol{N} & \mathrm{D} & \mathrm{T} & \mathrm{V} & \mathrm{C} & \mathrm{K} & \mathrm{E} & \mathrm{D} & \mathrm{C} & \mathrm{E} & \mathrm{E} & \mathrm{S} & \mathrm{C} & \mathrm{D} & \mathrm{V} & \mathrm{K} & \mathrm{T} & \mathrm{K} & \mathrm{I} & \mathrm{T} & \mathrm{R} & \mathrm{E} & \mathrm{E}\end{array}$ Coiled-coil domain,

280 aaacatttcatgtgtagaaatttgcaaaattctattgtttcctacacalagaagtaccaaaaactactaaggaa

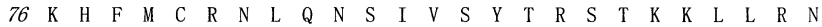
355 atgatggatgagcaacaagcttccttggattatttatctaatcaggttaacgagctcatgaatagagttctcctt $\begin{array}{lllllllllllllllllllllllllll}101 & \text { M } & \text { M } & \text { D } & \text { E } & \text { Q } & \text { Q } & \text { A } & \text { S } & \text { L } & \text { D } & \text { Y } & \text { L } & \text { S } & \text { N } & \text { Q } & \text { V } & \text { N } & \text { E } & \text { L } & \text { M } & \text { N } & \text { R } & \text { V } & \text { L } & \text { L }\end{array}$ Fibrinogen like domain

430 ttgactacagaagttttagaaaacagctggatccttttcctcacagacctgttcagtcacatggtttagattgc $\begin{array}{lllllllllllllllllllllllllllllllllll}126 & \mathrm{~L} & \mathrm{~T} & \mathrm{~T} & \mathrm{E} & \mathrm{V} & \mathrm{F} & \mathrm{R} & \mathrm{K} & \mathrm{Q} & \mathrm{L} & \mathrm{D} & \mathrm{P} & \mathrm{F} & \mathrm{P} & \mathrm{H} & \mathrm{R} & \mathrm{P} & \mathrm{V} & \mathrm{Q} & \mathrm{S} & \mathrm{H} & \mathrm{G} & \mathrm{L} & \mathrm{D} & \mathrm{C}\end{array}$ 505 actgatattaaggataccat tggetctgtcaccaaaacaccgagtggtttatacataattcacccagaaggatct $\begin{array}{llllllllllllllllllllllllll}151 & \mathrm{~T} & \mathrm{D} & \mathrm{I} & \mathrm{K} & \mathrm{D} & \mathrm{T} & \mathrm{I} & \mathrm{G} & \mathrm{S} & \mathrm{V} & \mathrm{T} & \mathrm{K} & \mathrm{T} & \mathrm{P} & \mathrm{S} & \mathrm{G} & \mathrm{L} & \mathrm{Y} & \mathrm{I} & \mathrm{I} & \mathrm{H} & \mathrm{P} & \mathrm{E} & \mathrm{G} & \mathrm{S}\end{array}$ 580 agctacccatttgaggtaatgtgtgacatggattacagaggaggtggatggactg tgatacagaaaagaat tgat $\begin{array}{llllllllllllllllllllllllll}176 & \mathrm{~S} & \mathrm{Y} & \mathrm{P} & \mathrm{F} & \mathrm{E} & \mathrm{V} & \mathrm{M} & \mathrm{C} & \mathrm{D} & \mathrm{M} & \mathrm{D} & \mathrm{Y} & \mathrm{R} & \mathrm{G} & \mathrm{G} & \mathrm{G} & \mathrm{W} & \mathrm{T} & \mathrm{V} & \mathrm{I} & \mathrm{Q} & \mathrm{K} & \mathrm{R} & \mathrm{I} & \mathrm{D}\end{array}$ 655 gggataattgatttccagaggttgtggtgtgattatctggatggatttggagatcttctaggagaattttggcta

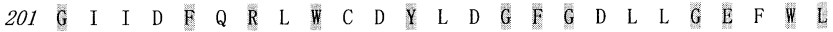
730 ggactgaaaagattttttatatagtaaatcagaaaaataccagttttatgctgtatgtggctttggaatctgaa $\begin{array}{llllllllllllllllllllllllll}226 & G & \text { L } & K & K & \text { I } & F & Y & \text { I } & \text { V } & \text { N } & \text { Q } & \text { K } & \text { N } & \text { T } & \text { S } & \text { F } & \text { M } & \text { L } & \text { Y } & \text { V } & \text { A } & \text { L } & \text { E } & \text { S } & \text { E }\end{array}$ 805 gatgacactcttgcttatgcatcatatgataatttttggctagaggatgaaacgagattttttaaaatgcactta $\begin{array}{lllllllllllllllllllllllllll}251 & \text { D } & D & T & L & A & Y & A & S & Y & D & N & F & W & L & E & D & E & T & R & F & F & K & M & H & L\end{array}$ 880 ggacggtattcaggaagtgctggtgatgcattccggggtctcaaaaagaagataatcaaaatgcaatgcctttt $\begin{array}{lllllllllllllllllllllllllll}276 & G & R & Y & S & G & S & A & G & D & A & F & R & G & L & K & K & E & D & N & Q & N & A & M & P & F\end{array}$ 955 agcacatcagatgttgataatgatgggtgtcgccetgcatgcctggtcaatggtcagtctgtgaagagctgcagt $\begin{array}{llllllllllllllllllllllllll}301 & \mathrm{~S} & \mathrm{~T} & \mathrm{~S} & \mathrm{D} & \mathrm{V} & \mathrm{D} & \mathrm{N} & \mathrm{D} & \mathrm{G} & \mathrm{C} & \mathrm{R} & \mathrm{P} & \mathrm{A} & \mathrm{C} & \mathrm{L} & \mathrm{V} & \mathrm{N} & \mathrm{G} & \mathrm{Q} & \mathrm{S} & \mathrm{V} & \mathrm{K} & \mathrm{S} & \mathrm{C} & \mathrm{S}\end{array}$ 1030 cacctccataacaagaccggctggtggtt taacgagtgtggtctagcaaatctaaatggcattcatcacttctct $\begin{array}{llllllllllllllllllllllllll}326 & \text { H } & \text { L } & \text { H } & N & \text { K } & \text { T } & G & \text { WI } & \text { W } & \text { F } & \text { N } & \text { E } & \text { C } & \text { G } & \text { L } & \text { A } & \text { N } & \text { L } & \text { N } & \text { G } & \text { I } & \text { H } & \text { H } & \text { F } & \text { S }\end{array}$ 1105 ggaaaat tgct tgcaactggaattcaatggggcacgtggaccaaaaacaactcacctgtcaagat taaatctgtt $\begin{array}{lllllllllllllllllllllllllll}351 & G & K & \text { L } & \text { L } & \text { A } & \text { T } & G & \text { I } & \text { Q } & \text { W } & G & \text { T } & \text { W } & \text { T } & \text { K } & \text { N } & \text { N } & \text { S } & \text { P } & \text { V } & \text { K } & \text { I } & \text { K } & \text { S } & \text { V }\end{array}$ 1180 tcaatgaaaattagaagaatgtacaatccatattttaaataatctcatttaacattgtaatgcaagttctacaat $\begin{array}{lllllllllllllllllll}376 & \mathrm{~S} & \mathrm{M} & \mathrm{K} & \mathrm{I} & \mathrm{R} & \mathrm{R} & \mathrm{M} & \mathrm{Y} & \mathrm{N} & \mathrm{P} & \mathrm{Y} & \mathrm{F} & \mathrm{K} & *\end{array}$

1255 gataatatattaaagatttttaaaagtttatcttttcacttagtgtttcaaacatattaggcaaaatttaactgt 1330 agatggcatttagatgatatgagtt taat tagaaaact tcaattttgtagtattctataaaagaaaacatggct 1405 attgtatgtttttacttctgactatattaacaatatacaatgaaatttgtttcaagtgaactacaacttgtcttc 1480 ctaaaatttatagtgattttaaaggattttgccttttctttgaagcatttttaaaccataatatgttgtaaggaa 1555 aattgaagggaatattttacttatttttatactt tatatgat tatataatctacagataatttctactgaagaca 1630 gttacaataaataactttatgcagat taatatataagctacacatgatgtaaaacct tactatttctaggtgat 1705 gccataccattttaaaagtagtaagag ttgctgcccaaatagttttcttgttttcatatctaatcatggttaa 1780 ctatttgttattgtctgtaataaatatgtacttttatatcct

Fig. 1a,b. The sequence and structure of $A N G P T L 5$. a The nucleotide sequence and deduced amino acid sequence of ANGPTL5. The inframe codon and polyadenylation signals are shown in bold. Amino acids are represented below the DNA sequences. The asterisk represents the stop codon. The signal peptide sequence predicted by computer analysis using the SignalP program is shown in the box. Amino acid residues identical to at least seven of the following eight most

proteins show the common characteristic structure of angiopoietins and show homology with them. However, they do not bind to TIE2 and might have a different function from angiopoietins. For example, ANGPTL4 (also known as $P G A R$ or $F I A F$ ), which is regulated by the peroxisome proliferator-activated receptor $\alpha(P P A R \alpha)$, was identified as a fasting-induced adipose factor (Kersten et al. 2000). Recently, both ANGPTL3 and ANGPTL4 were found to function as a new class of lipid metabolism modulators (Koishi et al. 2002; Shimizugawa et al. 2002; Yoshida et al. 2002). Thus, we term this gene human angiopoietinlike 5 (ANGPTL5) in agreement with the HUGO Nomenclature Committee.

Like the other members of the angiopoietin family, $A N G P T L 5$-deduced protein has also been predicted to have an N-terminal cleavable signal peptide (PSORT II

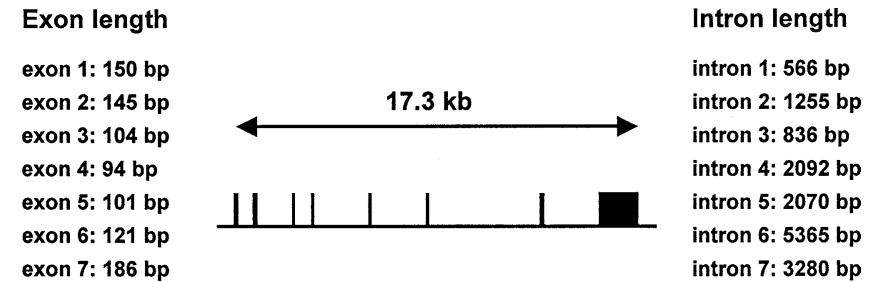

exon 8: 923 bp

b

related proteins are shaded: ANGPT1, ANGPT2, mANGPT3, ANGPT4, ANGPTL1, ANGPTL2, ANGPTL3, and ANGPTL4. The two arrows limit the coiled-coil domain and fibrinogen-like domain, respectively. Two potential glycosylation sites predicted by NetNGlyc 1.0 are shown in bold italic. b Genomic organization of the ANGPTL5 gene. The length of each exon and each intron is shown. The start codon is present in the first exon

server, http://psort.nibb.ac.jp: 8800), a predicted coiledcoil domain (COILS program web server, http:// www1.york.ac.uk/depts/biol/units/coils/coilcoil.html), and a fibrinogen-like domain (Bioinformatics Web server, http:// www.isrec.isb-sib.ch/software/PFSCAN_form.html) (Fig. 1a). The fibrinogen-like domain is conserved and is supposed to be the receptor-binding site (Valenzuela et al. 1999). The coiled-coil domain is related to oligomerization, which is very important to angiopoietins because oligomerization appears to be required for the functioning of angiopoietins (Maisonpierre et al. 1997).

By searching against the human EST database and the human genome database, we found that the ANGPTL5 gene is represented by six ESTs and three genomic sequences (accession no. NT_009151.12, AP002372.3, and AP003383.2) from chromosome 11q22. Comparison of the 


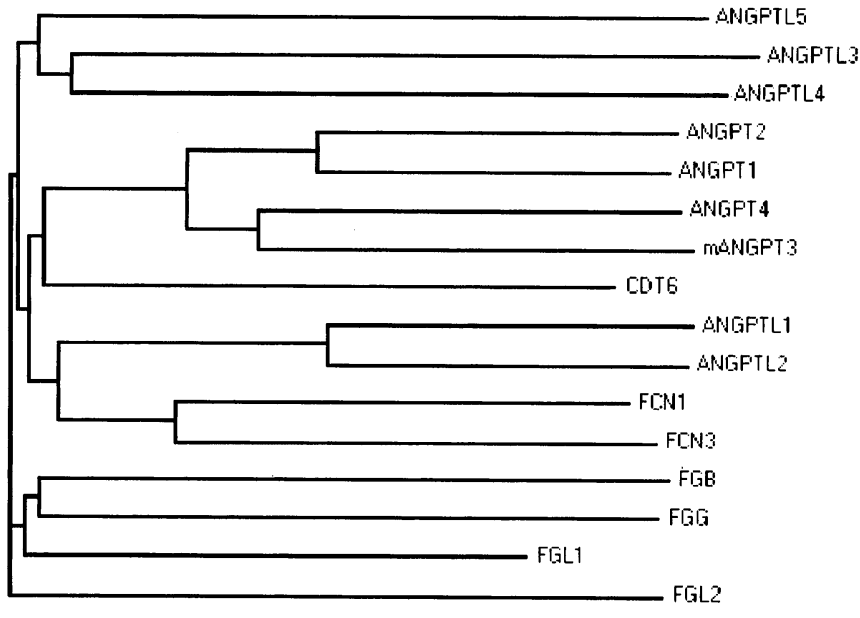

Fig. 2. A gene tree representing ANGPTL5 and its related sequences, including angiopoietins, angiopoietin-like genes, fibrinogen (beta and gamma polypeptide), and fibrinogen-like genes. The gene tree was generated using the AlignX program of Vector NTI suite 5.5. Sequence data were derived from GenBank as the following accession numbers: ANGPTL5 (our sequence), NP_055310, NP_057193, O15123, Q15389, NP_057069, AAD21586, CAA76078, NP_004664, NP_036230, NP_001994, NP_003656, NP_005132, NP_068656, NP_004458, and NP_006673 (from top to bottom)

cDNA sequence of ANGPTL5 to the genomic sequence revealed that this gene spans about $17.3 \mathrm{~kb}$ of genomic DNA and consists of eight exons (Fig. 1b). All sequences of the exon-intron junctions are consistent with the AG-GT rule. Moreover, a $\mathrm{CpG}$ island ( -835 to -629$)$ and a potential transcription promotor region $(-312$ to -262$)$ were found just before the first exon (predicted at http://125.itba.mi.cnr.it/genebin/wwwcpg.pl and http:// www.fruitfly.org/seq_tools/promotor.html, respectively).

To investigate the expression pattern of ANGPTL5 in different tissues, we used two human multiple tissue cDNA (MTC, Clontech, Palo Alto, CA, USA) panels as Polymerase Chain Reaction (PCR) templates according to the manufacturer's protocol. The ANGPTL5-specific primer pairs (ANGPTL5F: 5'-aggttgtggtgtgattatctggatgg-3' and ANGPTL5R: 5'-actcatatcatctaaatgccatctacag-3') were designed to amplify a $0.7-\mathrm{kb}$ fragment. A glyceraldehyde-3phosphate dehydrogenase $(G 3 P D H)$ control primer pair included in the panels was used to verify the normalization of the MTC panels. A total of 35 cycles of amplification was performed using rTaq DNA polymerase (TaKaRa, Shiga, Japan) in a total volume of $50 \mu l$. All the reactions were paused after a total of 24 cycles, 27 cycles, 30 cycles, 33 cycles, and 35 cycles. At each pause, a 5- $\mu \mathrm{l}$ sample of every reaction mixure was removed to run on a gel, and the rest were put back in the thermal cycler. The cycling conditions were as follows: $5 \mathrm{~min}$ at $94^{\circ} \mathrm{C}$, followed by cycles of $30 \mathrm{~s}$ at $94^{\circ} \mathrm{C}$ and $90 \mathrm{~s}$ at $68^{\circ} \mathrm{C}$, with a 5 -min $68^{\circ} \mathrm{C}$ step to finish. When 24 cycles of amplification had been performed, G3PDH (positive control) reverse transcriptase (RT)-PCR products were detected in all tissues tested. After 35 cycles, $A N G P T L 5$ RT-PCR products were only detected in adult

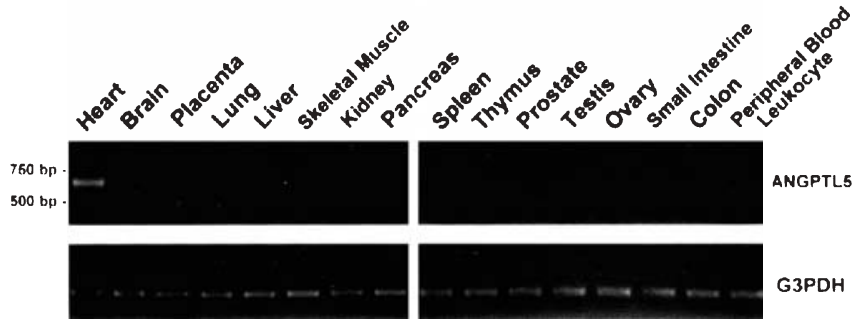

Fig. 3. Reverse transcription-polymerase chain reaction analysis of human adult tissue cDNA for ANGPTL5 and G3PDH (positive control). Results of 35 cycles (for ANGPTL5) and 24 cycles (for G3PDH) of amplification are shown

human heart (Fig. 3). Further study should be made to clarify the precise role of the ANGPTL5 gene.

\section{References}

Conklin D, Gilbertson D, Taft DW, Maurer MF, Whitmore TE, Smith DL, Walker KM, Chen LH, Wattler S, Nehls M, Lewis KB (1999) Identification of a mammalian angiopoietin-related protein expressed specifically in liver. Genomics 62:477-482

Davis S, Aldrich TH, Jones PF, Acheson A, Compton DL, Jain V, Ryan TE, Bruno J, Radziejewske C, Maisonpierre PC, Yancopoulos GD (1996) Isolation of angiopoietin-1, a ligand for the TIE2 receptor, by scretion-trap expression cloning. Cell 87:1161-1169

Hanahan D, Folkman J (1996) Patterns and emerging mechanisms of the angiogenic switch during tumorigenesis. Cell 86:353-364

Kersten S, Mandard S, Tan NS, Escher P, Metzger D, Chambon P, Gonzalez FJ, Desvergne B, Wahli W (2000) Characterization of the fasting-induced adipose factor FIAF, a novel peroxisome proliferator-activated receptor target gene. J Biol Chem 275:2848828493

Kim I, Kwak HJ, Ahn JE, So JN, Liu M, Koh KN, Kon GY (1999a) Molecular cloning and characterization of a novel angiopoietin family protein, angiopoietin-3. FEBS Lett 443:353-356

Kim I, Moon SO, Koh KN, Kim H, Uhm CS, Kwak HJ, Kim NG, Koh GY (1999b) Molecular cloning, expression, and characterization of angiopoietin-related protein. Angiopoietin-related protein induces endothelial cell sprouting. J Biol Chem 274:26523-26528

Kim I, Kim HG, Kim H, Kim HH, Park SK, Uhm CS, Lee ZH, Koh GY (2000) Hepatic expression, synthesis and secretion of a novel fibrinogen/angiopoietin-related protein that prevents endothelial-cell apoptosis. Biochem J 346:603-610

Koishi R, Ando Y, Ono M, Shimamura M, Yasumo H, Fujiwara T, Horikoshi H, Furukawa H (2002) Angptl3 regulates lipid metabolism in mice. Nat Genet 30:151-157

Maisonpierre PC, Suri C, Jones PF, Bartunkova S, Wiegand SJ, Radziejewski C, Compton D, McClain J, Aldrich TH, Papadopoulos N, Daly TJ, Davis S, Sato TN, Yancopoulos GD (1997) Angiopoietin-2, a natural antagonist for Tie2 that disrupts in vivo angiogenesis. Science: 277:55-60

Nishimura M, Miki T, Yashima R, Yokoi N, Yano H, Sato Y, Seino S (1999) Angiopoietin-3, a novel member of the angiopoietin family. FEBS Lett 448:254-256

Shimizugawa T, Ono M, Shimamura M, Yoshida K, Ando Y, Koishi R, Ueda K, Inaba T, Minekura H, Kohama T, Furukawa H (2002) ANGPTL3 decreases very low density lipoprotein triglyceride clearance by inhibition of lipoprotein lipase. J Biol Chem 277:3374233748

Suri C, Jones PF, Patan S, Bartunkova S, Maisonpierre PC, Davis S, Sato TN, Yancopoulos GD (1996) Requisite role of angiopoietin-1, a ligand for the TIE2 receptor, during embryonic angiogenesis. Cell 87:1171-1180

Valenzuela DM, Griffiths JA, Rojas J, Aldrich TH, Jones PF, Zhou H, McClain J, Copeland NG, Gilbert DJ, Jenkins NA, Huang T, 
Papadopoulos N, Maisonpierre PC, Davis S, Yancopoulos GD (1999) Angiopoietins 3 and 4: diverging gene counterparts in mice and humans. Proc Natl Acad Sci USA 96:1904-1909

Xu J, Zhou Z, Zeng L, Huang Y, Zhao W, Cheng C, Xu M, Xie Y, Mao $\mathrm{Y}$ (2001) Cloning, expression and chracterization of a novel human REPS1 gene. Biochem Biophys Acta 1522:118-121
Yoshida K, Shimizugawa T, Ono M, Furukawa H (2002) Angiopoietinlike protein 4 is a potent hyperlipidemia-inducing factor in mice and inhibitor of lipoprotein lipase. J Lipid Res 43:1770-1772 